\title{
Crescimento e qualidade de mudas de diferentes cultivares de cafeeiro sob diferentes substratos e recipientes
}

\author{
Growth and quality of seedlings of different coffee cultivars under different substrates and \\ containers
}

Crecimiento y calidad de plántulas de diferentes cultivares de café bajo diferentes sustratos y contenedores

\section{Resumo}

O objetivo foi avaliar os efeitos dos recipientes e substratos no crescimento e na qualidade de mudas de cafeeiro em diferentes cultivares. O experimento foi conduzido no setor de produção de mudas do Ifsuldeminas - Campus Inconfidentes, Inconfidentes/MG, em um delineamento de blocos casualizados com três repetições por tratamento, sendo as parcelas constituídas por 30 plantas. O esquema fatorial foi de 2 × 2 × 5 sendo constituídos por dois recipientes, dois tipos de substratos e cinco cultivares de cafeeiro. Foram avaliados os parâmetros de crescimento e qualidade das mudas. Os resultados obtidos permitiram verificar que para a produção de mudas, os recipientes e os substratos interfere no crescimento das mudas cafeeiras, apresentando melhor qualidade as mudas no recipiente tubete com a utilização do substrato comercial, sendo a cultivar Acauã e a cultivar Topázio 1190, produzida em sacolas com substrato comercial com melhores resultados. Pela análise multivariada verificou-se que o maior crescimento das mudas em altura e menor diâmetro de coleto foi responsável pela menor qualidade das mesmas. Diante disso, conclui-se que o saquinho preenchidos com substrato comercial, proporcionou mudas com maior crescimento. $\mathrm{O}$ tubete, preenchido com substrato comercial, proporcionou mudas de melhor qualidade; a cultivar que apresentou um maior desequilíbrio foi a Catuaí 144, no saquinho; as cultivares que apresentam melhores IQD são a Acauã com uso de tubete em substrato comercial e a Topázio 1190 na sacolinha; a variável que mais contribui para o IQD foi a MSSR; o substrato padrão limitou o crescimento das raízes.

Palavras-chave: Coffea arabica; Tubetes; IQD; Cafeicultura; Análise de componentes principais.

\section{Abstract}

The objective was to evaluate the effects of containers and substrates on the growth and quality of coffee seedlings in different cultivars. The experiment was conducted in the seedling production sector of Ifsuldeminas - Campus Inconfidentes, Inconfidentes /MG, in a randomized block design with three replications per treatment, with the parcels consisting of 30 plants. The factorial scheme was $2 \times 2 \times 5$ and consisted of two containers, two types of substrates and 
five coffee cultivars. Seedling growth and quality parameters were evaluated. The results obtained allowed to verify that for the production of seedlings, the containers and substrates interfere in the growth of the coffee seedlings, presenting the seedlings in the tube container with better quality using the commercial substrate, being the cultivar Acauã and the cultivar Topázio 1190, produced in bags with commercial substrate with better results. By multivariate analysis, it was found that the highest growth of seedlings in height and smallest collection diameter was responsible for their lower quality. Therefore, it is concluded that the bag filled with commercial substrate, provided seedlings with greater growth. The tube, filled with commercial substrate, provided better quality seedlings; the cultivar that showed the greatest imbalance was Catuaí 144, in the sachet; the cultivars with the best IQD are Acauã using a tube on a commercial substrate and Topázio 1190 in the bag; the variable that contributed most to the IQD was the MSSR; the standard substrate limited root growth.

Keywords: Coffea arabica; Tubes; IQD; Coffee cultivation; Principal component analysis.

\section{Resumen}

El objetivo fue evaluar los efectos de recipientes y sustratos sobre el crecimiento y calidad de plántulas de café en diferentes cultivares. El experimento se realizó en el sector de producción de plántulas de Ifsuldeminas - Campus Inconfidentes, Inconfidentes / MG, en un diseño de bloques al azar con tres repeticiones por tratamiento, siendo las parcelas de 30 plantas. El esquema factorial fue de 2 × 2 x 5 y consistió en dos contenedores, dos tipos de sustratos y cinco cultivares de café. Se evaluaron los parámetros de crecimiento y calidad de las plántulas. Los resultados obtenidos permitieron comprobar que, para la producción de plántulas, los contenedores y sustratos interfieren en el crecimiento de las plántulas de café, presentando mejor calidad las plántulas en el contenedor tubular con el uso del sustrato comercial, siendo el cultivar Acauã y el cultivar Topázio 1190, producido en bolsas con sustrato comercial con mejores resultados. Mediante análisis multivariado se encontró que el mayor crecimiento de plántulas en altura y menor diámetro de recolección fue responsable de su menor calidad. Por tanto, se concluye que la bolsa llena de sustrato comercial, proporcionó a las plántulas un mayor crecimiento. El tubo, lleno de sustrato comercial, proporcionó plántulas de mejor calidad; el cultivar que mostró mayor desequilibrio fue Catuaí 144, en sobre; los cultivares con mejor IQD son Acauã usando un tubo sobre un sustrato comercial y Topázio 1190 en la bolsa; la variable que más contribuyó al IQD fue la MSSR; el sustrato estándar limita el crecimiento de las raíces.

Palabras clave: Coffea arabica; Tubos; IQD; Cultivo de café; Análisis de componentes principales.

\section{Introdução}

A escolha de cultivares de café é um fator de grande importância, devido aos aspectos morfofisiológicos do cafeeiro como oscilação de produção; ciclo de produção longo; expressão dos caracteres ao longo de vários anos, interação genótipos x ambientes e diferenças em precocidade e longevidade produtiva (Pereira et al., 2013). Portanto é preciso levar em consideração fatores relacionados à produtividade, rusticidade e principalmente, a adaptabilidade para as mais diversas condições edafoclimáticas.

Grande parte das cultivares recomendadas para o plantio no atual cenário brasileiro apresentam boas características genotípicas. Das mais de 130 cultivares de café arábica existente (Mapa, 2019), ainda há um predomínio do plantio das cultivares Mundo Novo e Catuaí, representando 90\% do parque cafeeiro (Matiello et al., 2005), as quais não são resistentes as principais pragas e doenças da cultura.

Para reverter este cenário é necessário, em escala comercial, a seleção, recomendação e utilização de novas linhagens com elevado potencial de produção, excelente vigor vegetativo, uniformidade de maturação e boa qualidade de bebida (Dias et al., 2005) sendo estas resistentes às principais pragas e doenças da cultura.

Além da seleção de cultivares mais adequadas para cada região se faz necessário o uso de mudas de qualidade, sendo este o primeiro passo para obter uma lavoura cafeeira produtiva. $\mathrm{O}$ investimento da pesquisa e dos produtores na produção de mudas de qualidade é necessário, pois, entre os anos de 2008 a 2018 houve um aumento de 96.000 hectares de novas lavouras devido à expansão, formação ou renovação de lavouras de café (Conab, 2018).

A produção nacional de mudas de café ainda está baseada no uso de sacolas de polietileno. Apesar do custo inicial ser um forte apelo aos viveiristas, esses recipientes trazem o inconveniente de necessitarem de maior volume de substrato, o que aumenta a área do viveiro e dificulta o manejo, especialmente com relação às práticas de irrigação, mondas, o transporte para o campo e a decorrente distribuição para o plantio na lavoura (Marana et al., 2008). Além disso, a maior quantidade do substrato 
é constituído por terra e matéria orgânica o que amplia a possibilidade de disseminação de pragas e doenças, o que inviabiliza futuros cultivos.

O uso de tubetes ainda apresenta limitações na adoção pelos viveiristas, pois seu custo inicial maior e a necessidade de construção de suportes para sua condução, onera a instalação do viveiro. Por outro lado, o uso de tubetes constitui-se em uma alternativa para tentar solucionar alguns problemas. Tais recipientes já vêm sendo utilizados com sucesso, em viveiros de pinus e de eucaliptos, com redução nos custos de produção de aproximadamente $50 \%$ para mudas florestais. A produção de mudas de café em tubetes e o uso de substratos alternativos vêm sendo efetuadas desde 1989, porém com pouca adesão por parte dos produtores no uso desta tecnologia (Cunha et al., 2002). Com o uso deste recipiente o substrato mais utilizado é o comercial, contudo de valor mais elevado para sua aquisição.

Diante disso, os critérios a serem adotados para o uso dos substratos nos tubetes devem ser reavaliados, visto a sua importância para a produção de mudas de qualidade, com menor custo em menor tempo. Para escolha destes deve-se levar em consideração alguns critérios como nutrição, aeração, homogeneidade, baixa densidade, boa capacidade de retenção de água, além de fácil manipulação em todas as etapas, do viveiro ao campo (Gomes; Silva, 2004).

Estes substratos podem ser formados por diferentes matérias-primas de origem mineral, orgânica e até mesmo sintética (Vallone, 2003). Contudo, dependendo da sua composição, são insuficientes no fornecimento de nutrientes, sendo necessário o incremento de fertilizantes de liberação controlada para que os níveis nutricionais sejam ideais para promover o crescimento e manutenção das plantas.

Devido a importância da escolha correta dos recipientes e substratos para a produção de mudas de café, este trabalho objetiva avaliar os efeitos dos recipientes e substratos no crescimento e na qualidade de mudas de cafeeiro em diferentes cultivares.

\section{Metodologia}

O experimento foi instalado e conduzido no município de Inconfidentes - MG, no setor de viveiricultura da Fazenda Escola do Ifsuldeminas, Campus Inconfidentes, localizado a uma altitude de $869 \mathrm{~m}$, latitude $22^{\circ} 10^{\prime} 01$ ' S, longitude $46^{\circ} 19^{\prime}$ 40" O. O clima da região é Tropical Úmido (Cwb), segundo a classificação de W. Köppen. Foi conduzido no período de setembro de 2017 a fevereiro de 2018.

Usou-se o delineamento de blocos casualizados em esquema fatorial de $2 \times 2 \times 5$ (dois tipos de recipientes, duas formulações de substrato e cinco cultivares de café, totalizando vinte tratamentos com três repetições. A parcela foi composta de trinta mudas, sendo as doze centrais consideradas como área útil.

Foram utilizados dois recipientes para a condução do ensaio, sendo eles: tubetes de polipropileno rígido com capacidade volumétrica de $120 \mathrm{ml}$, de formato cônico, com seu diâmetro superior interno de 3,7 cm, 0,8 cm de diâmetro inferior interno e com altura de $14 \mathrm{~cm}$ e saquinhos de polietileno nas dimensões de $20 \mathrm{~cm}$ de altura por $10 \mathrm{~cm}$ de largura e capacidade volumétrica de $700 \mathrm{ml}$.

Foram testadas duas formulações de substratos no experimento. O substrato comercial utilizado foi Multiplant Café̊, da Terra Paraíso, sendo constituído de casca de pinus processada, vermiculita e turfa. O mesmo foi enriquecido com a dose recomendada do fertilizante de liberação controlada, Osmocote 15-09-12 (6 gramas/ Litro).

Utilizou-se também o substrato padrão, composto por $70 \%$ de terra, $30 \%$ de esterco bovino, $5 \mathrm{Kg}$ de Superfosfato Simples e $1 \mathrm{Kg}$ de Cloreto de Potássio (Andrade Neto et al, 1999).

As cultivares utilizadas no experimento foram Acauã, Arara, Catuaí 144, Catucaí 2 SL e a Topázio MG 1190. As sementes foram adquiridas na Fundação Procafé, na cidade de Varginha- MG, na safra 2016/2017. 
Tanto os tubetes como os saquinhos foram colocados em um canteiro suspenso, a um metro de altura da superfície do solo, confeccionado com tela de arame ondulado com aberturas quadradas de 1,5”, arame de 3,5 mm de diâmetro e com $1 \mathrm{~m}$ de largura. Os tubetes foram esterilizados com solução de água e hipoclorito de sódio ( 2 a 2,5\% de concentração).

A cobertura foi feita com sombrite de cor preta com passagem de 50\% da luz, colocada a dois metros e meio de altura em relação ao solo. As irrigações foram feitas duas vezes ao dia utilizando o sistema de irrigação de microaspersão suspensa, mantendo o substrato próximo à capacidade de campo.

No momento da semeadura, tanto nos saquinhos plásticos quanto nos tubetes, foram depositadas três sementes de café por recipiente a uma profundidade de dois centímetros.

O desbaste das mudas foi realizado quando estas se encontravam no estádio de folhas cotiledonares, iniciando a emissão do primeiro par de folhas verdadeiras nas parcelas, eliminando aquelas menos vigorosas e deixando apenas uma muda por recipiente.

As capinas foram feitas semanalmente de forma manual. Para o controle de pragas e doenças, optou-se por não realizálo de forma preventiva, para que não houvesse interferências nos resultados, não sendo necessário o controle curativo devido ao não aparecimento das mesmas durante a condução do ensaio.

O experimento foi encerrado aos 150 dias, sendo avaliadas as seguintes características: altura das plantas (AP): medidas no colo da planta até o meristema apical do ramo ortotrópico, obtendo-se a medida por planta em centímetros; massa seca da parte aérea (MSPA) e massa seca do sistema radicular (MSSR): as plantas foram retiradas dos recipientes e lavadas em água. Em seguida, separou-se o sistema radicular da parte aérea, cortando-se o caule na altura do colo, as amostras de raízes foram acondicionadas em sacos de papel, sendo em seguida colocadas para secar em estufa à $60^{\circ}$, até atingirem massa constante. Posteriormente foi mensurada a massa em balança de precisão, obtendo o valor em gramas por planta; RPAR: relação da matéria seca da parte aérea com a matéria seca de raízes; RAD: relação da altura da parte aérea com o diâmetro do coleto; IQD: índice de qualidade de Dickson obtido pela fórmula; IQD = [matéria seca total/(RAD + RPAR)] (Dickson et al., 1960); IAF índice de área foliar: A área foliar das cultivares foi estimada com base na equação proposta por Barros et al. (1973): ÂF = 0,667.C.L, onde ÂF corresponde a estimativa da área foliar $\left(\mathrm{cm}^{2}\right)$; C é o comprimento da nervura central $(\mathrm{cm})$ e L é a máxima largura do limbo foliar (cm).

Os resultados foram submetidos à análise de variância, sendo as médias comparadas pelo teste de Tukey ao nível de 5\% de significância, usando-se o programa Sisvar 4.2 (Ferreira, 2014). As análises multivariadas foram utilizadas na interpretação do conjunto de dados obtidos, por meio software Genes (Cruz, 2013). A partir do dendrograma gerado no agrupamento hierárquico (UPGMA) pela distância generalizada de mahalanobis, objetivou-se identificar possíveis dissimilaridades entre os tratamentos. A análise dos componentes principais foi realizada com a finalidade de identificar as correlações existentes entre as variáveis e os tratamentos. Foi aplicado o critério de Singh (1981) para quantificar a contribuição das características para a divergência entre os tratamentos. Para todas as análises, considerou-se os dados médios de todas as variáveis estudadas.

\section{Resultados e Discussão}

$\mathrm{Na}$ Tabela 1 são apresentados os resultados do resumo da análise de variância para as características de crescimento e qualidade de mudas de cafeeiro em função da utilização de diferentes recipientes, substratos e cultivares. Nota-se que houve interação tripla para altura de plantas e IAF. A interação dupla foi verificada para MSPA, MSSR, RPAR, RAD e IQD. Nesta interação o comportamento que mais interferiu no crescimento e qualidade das mudas foram os fatores recipiente e substrato. Ou seja, independente da variável e das cultivares analisadas, estas são influenciadas por mais de um dos fatores em estudo a qual pode resultar em qualidades distintas das mudas (Tabela 1). 
Tabela 1. Resumo da análise de variância, dos parâmetros de crescimento e qualidade de mudas de cafeeiro: altura de planta em $\mathrm{cm}$ (AP), índice de área foliar em $\mathrm{cm}^{2}$ (IAF), massa seca de parte aérea em gramas (MSPA), massa seca do sistema radicular em gramas (MSSR), massa seca de raízes (RPAR), relação da altura da parte aérea com o diâmetro do coleto (RAD), Índice de qualidade de Dickson (IQD) em cultivares de mudas de café arábica em diferentes recipientes e substratos, Inconfidentes- MG, 2017.

\begin{tabular}{ccccccccc}
\hline \multirow{2}{*}{ FV } & \multirow{2}{*}{ GL } & \multicolumn{7}{c}{ Características avaliadas $(\mathrm{p} \leq 0,05)$} \\
\cline { 3 - 8 } & & AP & IAF & MSPA & MSSR & RPAR & RAD & IQD \\
\hline Recipiente (R) & 1 & 0,00 & 0,00 & 0,00 & 0,00 & 0,00 & 0,00 & 0,00 \\
Substrato (S) & 1 & 0,00 & 0,00 & 0,00 & 0,00 & 0,00 & 0,00 & 0,00 \\
Cultivar (C) & 4 & 0,00 & 0,13 & 0,0 & 0,03 & 0,01 & 0,00 & 0,00 \\
R x S & 1 & 0,00 & 0,00 & 0,00 & 0,00 & 0,01 & 0,00 & 0,00 \\
R x C & 4 & 0,00 & 0,33 & 0,00 & 0,61 & 0,01 & 0,01 & 0,08 \\
S x C & 4 & 0,72 & 0,10 & 0,00 & 0,08 & 0,96 & 0,21 & 0,01 \\
R x S x C & 4 & 0,01 & 0,01 & 0,06 & 0,30 & 0,38 & 0,21 & 0,18 \\
CV (\%) & & 4,74 & 13.10 & 6,30 & 10,73 & 10,62 & 6,01 & 8,53 \\
\hline
\end{tabular}

Fonte: Autores (2020).

Os resultados do desdobramento da interação tripla: recipiente dentro de substrato e cultivar (R: S-C), substrato dentro de cultivar e recipiente (S: C-R) e para cultivar dentro de recipiente e substrato (C: R-S) estão nas Tabelas 2 e 3.

Na interação R: S-C (Tabela 2), verifica-se de uma maneira geral que o recipiente de maior volume proporciona aumento na altura das plantas para todas as cultivares, independente do substrato utilizado. Tais valores permitem inferir que a característica altura de planta é fortemente influenciada pelo tamanho do recipiente, independente do genótipo utilizado e dos substratos que são submetidos.

Já quando as mudas foram produzidas dentro do tubete, (Tabela 2) demonstrou estatisticamente que o substrato comercial apresentou os maiores valores de altura, quando comparado ao padrão, sendo este resultado independentemente da cultivar utilizada. Já para o saquinho as cultivares não obtiveram diferença entre os substratos, excetuando-se a cultivar Catucaí 2 SL que obteve uma superioridade quando se utilizou o substrato comercial, com um ganho de 1,32 cm, quando comparado ao substrato padrão. 
Tabela 2. Parâmetros de crescimento: altura de planta (AP), em cm, índice de área foliar (IAF), em $\mathrm{cm}^{2}$ e para a interação: substratos (S), recipientes e cultivar (C) em mudas de café arábica, Inconfidentes- MG.

\begin{tabular}{ccccc}
\hline & & AP & & IAF \\
\hline S -C & Tubete & Saquinho & Tubete & Saquinho \\
Comercial - Acauã & $10,04 \mathrm{Ab}$ & $13,35 \mathrm{Aa}$ & $25,08 \mathrm{Ab}$ & $37,79 \mathrm{Aa}$ \\
Comercial - Arara & $11,31 \mathrm{Ab}$ & $13,26 \mathrm{Aa}$ & $24,10 \mathrm{Ab}$ & $38,10 \mathrm{Aa}$ \\
Comercial - Catuaí 144 & $11,01 \mathrm{Ab}$ & $13,95 \mathrm{Aa}$ & $26,92 \mathrm{Ab}$ & $29,43 \mathrm{Bb}$ \\
Comercial - Catucaí2 SL & $11,24 \mathrm{Ab}$ & $13,85 \mathrm{Aa}$ & $22,30 \mathrm{Ab}$ & $31,34 \mathrm{Ba}$ \\
Comercial - Topázio & $11,66 \mathrm{Ab}$ & $12,78 \mathrm{Aa}$ & $25,89 \mathrm{Ab}$ & $32,55 \mathrm{Ba}$ \\
Padrão - Acauã & $6,73 \mathrm{Bb}$ & $12,89 \mathrm{Aa}$ & $9,95 \mathrm{Bb}$ & $29,56 \mathrm{Ba}$ \\
Padrão - Arara & $7,53 \mathrm{Bb}$ & $13,94 \mathrm{Aa}$ & $4,64 \mathrm{Bb}$ & $26,69 \mathrm{Ba}$ \\
Padrão - Catuaí 144 & $7,66 \mathrm{Bb}$ & $14,44 \mathrm{Aa}$ & $4,11 \mathrm{Bb}$ & $29,78 \mathrm{Ba}$ \\
Padrão - Catucaí2 SL & $8,70 \mathrm{Bb}$ & $12,53 \mathrm{Ba}$ & $9,09 \mathrm{Bb}$ & $28,06 \mathrm{Ba}$ \\
Padrão - Topázio & $7,86 \mathrm{Bb}$ & $12,86 \mathrm{Aa}$ & $8,67 \mathrm{Bb}$ & $28,59 \mathrm{Ba}$ \\
\hline
\end{tabular}

*Médias seguidas das mesmas letras maiúsculas na coluna (S: C-R) e minúsculas na linha (R: S-C) não diferem entre si pelo teste de Tukey a $5 \%$ de significância.

Fonte: Autores (2020).

Dentre os recipientes utilizados o saquinho obteve maior crescimento independentemente do substrato e cultivares (Tabela 2). Esse maior crescimento vegetativo no saquinho, provavelmente está relacionado a fatores fisiológicos e nutricionais de cada cultivar, pois a maior quantidade de nutrientes e o maior espaço, propiciam melhores condições ao crescimento da parte aérea. Santinato et al. (2019) trabalhando com diferentes substratos em sacolinha em proporções diferentes para o esterco suíno, verificaram que todos apresentaram maior altura em relação ao substrato padrão, diferindo dos nossos resultados, a qual não demonstrou diferença significativa entre o substrato padrão e substrato comercial fertilizado com Osmocote (Tabela 2).

O desdobramento de recipiente dentro de substrato-cultivar (R: S-C) para a característica de índice de área foliar (IAF) está na Tabela 2. Percebe-se que as cultivares Acauã, Arara, Catucaí 2 SL e Topázio 1190 apresentaram os maiores valores de IAF no saquinho para ambos os substratos. A exceção foi a cultivar Catuaí 144, que foi igual estatisticamente para ambos os recipientes com o uso do substrato comercial. Ainda na Tabela 2, os substratos dentro do tubete se diferiram estatisticamente, sendo aquele que proporcionou maior área foliar das cultivares foi o de origem comercial, apresentando uma superioridade significativa, quando comparado com o substrato padrão.

Já para o substrato padrão dentro do tubete, na mesma interação (S:C-R), e na interação da Tabela 3 (C: R-S), estes resultados permitem inferi que quando as mudas foram submetidas ao tubete com substrato padrão acabou restringindo o crescimento da área foliar das plantas e altura das mudas (Tabela 2). É importante salientar que esse comportamento foi muito parecido com o obtido na altura de planta, provando a inviabilidade do crescimento vegetativo inicial de plantas oriundas desse conjunto (tubete: padrão), independente da cultivar. É importante salientar que esse comportamento foi muito parecido com o obtido na altura de planta, provando a inviabilidade do crescimento vegetativo inicial de plantas oriundas desse conjunto (tubete: substrato padrão), independente da cultivar, pois este tipo de substrato no tubete apresenta menor densidade formando uma camada compactada na superfície devido aos teores de argila e a irrigação, comprometendo o crescimento das mudas. 
Tabela 3. Parâmetro de crescimento: altura de planta (AP) em $\mathrm{cm}$ e índice de área foliar (IAF), em $\mathrm{cm}^{2}$ para o desdobramento de cultivar (C) dentro de recipiente (R) - substrato (S) (C: R- S) em mudas de café arábicas, Inconfidentes- MG.

\begin{tabular}{cccccc}
\hline & \multicolumn{5}{c}{ AP } \\
\hline $\mathrm{R}-\mathrm{S}$ & Acauã & Arara & Catuaí & Catucaí & Topázio \\
\hline Saquinho-Comercial & $13,35 \mathrm{~A}$ & $13,26 \mathrm{~A}$ & $13,95 \mathrm{~A}$ & $13,85 \mathrm{~A}$ & $12,78 \mathrm{~A}$ \\
Saquinho-Padrão & $12,89 \mathrm{C}$ & $13,94 \mathrm{~B}$ & $14,44 \mathrm{~A}$ & $12,53 \mathrm{D}$ & $12,86 \mathrm{C}$ \\
Tubete-Comercial & $10,04 \mathrm{C}$ & $11,31 \mathrm{~A}$ & $11,01 \mathrm{~B}$ & $11,24 \mathrm{~B}$ & $11,66 \mathrm{~A}$ \\
Tubete-Padrão & $6,73 \mathrm{C}$ & $7,53 \mathrm{~B}$ & $7,66 \mathrm{~B}$ & $8,70 \mathrm{~A}$ & $7,86 \mathrm{~B}$ \\
\hline & & & & \\
\hline $\mathrm{R}-\mathrm{S}$ & Acauã & Arara & Catuaí & Catucaí & Topázio \\
\hline Saquinho-Comercial & $37,79 \mathrm{~A}$ & $38,10 \mathrm{~A}$ & $29,43 \mathrm{C}$ & $31,34 \mathrm{~B}$ & $32,55 \mathrm{~B}$ \\
Saquinho-Padrão & $29,56 \mathrm{~A}$ & $26,69 \mathrm{~A}$ & $29,78 \mathrm{~A}$ & $28,06 \mathrm{~A}$ & $28,59 \mathrm{~A}$ \\
Tubete-Comercial & $25,08 \mathrm{~A}$ & $24,10 \mathrm{~A}$ & $26,92 \mathrm{~A}$ & $22,30 \mathrm{~A}$ & $25,89 \mathrm{~A}$ \\
Tubete-Padrão & $9,95 \mathrm{~A}$ & $4,64 \mathrm{~A}$ & $4,11 \mathrm{~A}$ & $9,09 \mathrm{~A}$ & $8,67 \mathrm{~A}$ \\
\hline
\end{tabular}

*Médias seguidas das mesmas letras maiúsculas na linha, não diferem entre si pelo teste de Tukey a 5\% de significância.

Fonte: Autores (2020).

Buscando identificar o desempenho da altura de cada cultivar dentro de recipiente e substrato (C: R-S) (Tabela 3), observou que não houve diferença significativa quando as mudas foram produzidas no saquinho com substrato comercial. Quanto ao desempenho das cultivares no saquinho com substrato padrão, a cultivar com melhor desempenho foi a Catuaí 144, apresentando uma diferença de 1,91 cm em relação a Catucaí 2 SL, que apresentou a menor média para esse desdobramento.

A significância da interação (C:R-S) (Tabela 3) mostra que o comportamento das cultivares é distinto quando produzidas no tubete, em ambos os substratos para a altura de plantas. Sendo que com o uso do tubete com substrato comercial, as cultivares Arara e Topázio se mostraram igualmente superiores. Nesta interação, a cultivar Acauã utilizando substrato comercial no tubete apresentou a menor média de altura $(10,04 \mathrm{~cm})$. Quando as mudas foram submetidas ao tubete com substrato padrão, a cultivar Catucaí 2 SL obteve melhor desempenho com uma superioridade de 22,64 \% em relação a Acauã, (Tabela 3) mostrando uma capacidade de adaptação, desta cultivar, ao crescimento vegetativo em recipiente de menor capacidade volumétrica com substrato padrão.

Verifica-se que o desdobramento C:R-S (Tabela 3) que proporcionou as maiores médias de IAF para as cultivares Acauã e Arara, foi o saquinho com substrato comercial. Já para as outras interações, não foi observado diferença entre as cultivares. Oliveira e Miglioranza (2015), relatam em sua pesquisa com mudas de café em diferentes tamanhos de recipientes de mesmo material, que ao aumentarem o tamanho do recipiente a uma expansão no tamanho das mudas e da área foliar.

Ao analisar a interação cultivar x substrato (Tabela 4) percebe-se que para a MSPA há uma superioridade das mudas provenientes do substrato comercial e na avaliação para a interação cultivares x recipiente, observamos os maiores valores para o saquinho, indicando que o crescimento vegetativo é favorecido quando as mesmas são submetidas ao substrato comercial com uso do saquinho em função do seu maior volume de substrato.

Para as cultivares verifica-se maior MSPA para a cultivar Acauã, com uma média de 10,31 g, no substrato comercial. Essa tendência de superioridade já tinha sido observada para o IAF. Já para o substrato padrão não foi observado diferença significativa para a massa seca de parte aérea, indicando uma independência entre os genótipos.

A interação cultivares x recipientes no parâmetro MSPA, nota-se que há uma significativa superioridade da Acauã no saquinho, apresentando uma média de 11,31g. Já a cultivar que obteve a pior média dentro do saquinho, foi a Catucaí 2 SL. 
Quando se trabalhou com tubete, as médias não evidenciaram diferença significativa para as cultivares produzidas (Tabela 4), indicando que os genótipos são pouco influenciados quando são submetidos a recipientes de menor volume.

Tabela 4. Parâmetro de crescimento: massa seca de parte área em gramas (MSPA) para a interação: cultivares x substrato, cultivares, $\mathrm{x}$ recipiente e recipiente $\mathrm{x}$ substrato; e massa seca do sistema radicular (MSSR) para a interação recipiente $\mathrm{x}$ substrato para de mudas de café arábica, Inconfidentes- MG.

\begin{tabular}{|c|c|c|c|c|c|c|c|c|}
\hline \multirow{2}{*}{${ }^{1}$ Sub. } & \multicolumn{5}{|c|}{ Cultivares } & \multicolumn{3}{|c|}{ Recipiente } \\
\hline & Acauã & Arara & Catuaí & Catucaí & Topázio & Sub. & Tub. & Saq. \\
\hline & \multicolumn{5}{|c|}{ MSPA (g) } & \multicolumn{3}{|c|}{ MSPA (g) } \\
\hline${ }^{2} \mathrm{Com}$. & $10,31 \mathrm{Aa}$ & $9,35 \mathrm{Ac}$ & $10,11 \mathrm{Ab}$ & $8,53 \mathrm{Ad}$ & 9,32Ac & Com. & $8,60 \mathrm{Ab}$ & $10,45 \mathrm{Aa}$ \\
\hline${ }^{3} \mathrm{Pad}$. & 7,57Ba & 7,48Ba & 7,44Ba & 7,61Ba & $7,68 \mathrm{Ba}$ & Pad. & $5,16 \mathrm{Bb}$ & $9,95 \mathrm{Ba}$ \\
\hline${ }^{4}$ Rec. & \multicolumn{5}{|c|}{ MSPA (g) } & \multicolumn{3}{|c|}{$\operatorname{MSSR}(\mathrm{g})$} \\
\hline${ }^{5}$ Tub. & $6,58 \mathrm{Ba}$ & $6,59 \mathrm{Ba}$ & $7,08 \mathrm{Ba}$ & $7,01 \mathrm{Ba}$ & $7,15 \mathrm{Ba}$ & Com. & $2,83 \mathrm{Aa}$ & $1,73 \mathrm{Ab}$ \\
\hline${ }^{6} \mathrm{Saq}$. & $11,31 \mathrm{Aa}$ & $10,25 \mathrm{Ac}$ & $10,46 \mathrm{Ab}$ & $9,13 \mathrm{Ae}$ & $9,85 \mathrm{Ad}$ & Pad. & $2,42 \mathrm{Ba}$ & $1,72 \mathrm{Ab}$ \\
\hline
\end{tabular}

${ }^{1}$ Substrato; ${ }^{2}$ Comercial; ${ }^{3}$ Padrão; ${ }^{4}$ Recipiente; ${ }^{5}$ Tubete; ${ }^{6}$ Saquinho. *Médias seguidas das mesmas letras maiúsculas na coluna e minúsculas na linha não diferem entre si pelo teste de Tukey a 5\% de significância. Fonte: Autores (2020).

$\mathrm{Na}$ interação recipiente $\mathrm{x}$ substrato, nota-se que as mudas produzidas em tubetes se desenvolveram menos em MSPA, do que as produzidas em sacolinhas independente do substrato utilizado, sendo o inverso observado para MSSR (Tabela 4), cuja maior média foi a favor do recipiente de menor capacidade volumétrica. Campos (2002); Cunha et al. (2002) e Vallone (2003) trabalhando com diferentes tamanhos de recipientes na produção de mudas, obtiveram uma superioridade para MSPA para aquelas submetidas a recipientes de maiores volumes. Já em função do uso dos substratos x recipiente, a MSPA (Tabela 4), mostra uma tendência semelhante às apresentadas em outras características, no qual o substrato padrão foi responsável pelo menor crescimento das mudas, em ambos os recipientes.

Esse mesmo resultado foi encontrado por Vallone (2006), que ao estudarem três substratos: alternativo, comercial e padrão, obtiveram os menores valores de massa seca quando as mudas foram submetidas ao substrato padrão. Santana et al. (2011), trabalhando com substrato comercial misturado com 35\% de diferentes fontes de resíduos orgânicos em tubetes em distintas cultivares de café, não verificaram diferença entre os tratamentos para as variáveis de crescimento.

Ao analisar a interação, substrato x recipiente, para MSSR (Tabela 4), é possível perceber um melhor ganho de massa da raiz no tubete com o uso do substrato comercial comparado ao substrato padrão. Isso possivelmente está associado a melhor acomodação do substrato Multiplant Café ${ }^{\circledR}$ dentro dos recipientes, no qual o substrato comercial não apresenta a consistência dura e compacta do substrato padrão. Esse maior ganho de MSSR no tubete acabou proporcionando um maior equilíbrio com a matéria seca de parte aérea sendo comprovado pelo RPAR (Tabela 5).

Tabela 5. Parâmetro de crescimento: média das cultivares para matéria seca do sistema radicular (MSSR) em mudas de café arábicas, Inconfidentes- MG.

\begin{tabular}{ccccc}
\hline & & Cultivar & & Catucaí \\
\hline Acauã & Arara & Catuaí & Topázio \\
\hline 2,29 A & & MSSR (g) & & \\
\hline
\end{tabular}

*Médias seguidas das mesmas letras maiúsculas na linha, não diferem entre si pelo teste de Tukey a 5\% de significância.

Fonte: Autores (2020). 
Neste sentido, Kampf (2002) tem razão em não recomendar a utilização de solo mineral em recipientes que suportam quantidades inferiores a $500 \mathrm{~mL}$ de substrato, devido às características físicas, que estão intimamente ligadas à densidade, aeração e retenção de água, o que poderia limitar o crescimento das raízes.

A altura das mudas e MSPA no saquinho para todos os tratamentos sempre foi maior do que no recipiente tubete, contudo a MSSR com o uso de tubete em ambos substratos em relação ao saquinho foram superiores (Tabela 4). Ou seja, as cultivares ficaram restritas ao crescimento da parte aérea da planta, a favor do sistema radicular. Isso porque, conforme pode ser observado (Tabela 4), a massa seca do sistema radicular é mais volumosa proporcionalmente quando as mudas são submetidas a recipientes de capacidade volumétrica menor, o que acaba reduzindo os valores do RPAR.

Estes resultados corroboram com os resultados de Samôr et al. (2002), que relatam que mudas cujo sistema radicular se encontram em condição de estresse, em função de recipientes de menor volume ou situação semelhante, acabam aumentando a alocação de seus fotoassimilados para as raízes, deixando de alocá-lo na parte aérea. Outros autores afirmam que está maior distribuição de fotoassimilados para o sistema radicular em função do estresse provocado pelo déficit hídrico favorece o crescimento radicular, com redução da perda de água por transpiração (Figueroa et al., 2004; Taiz; Zeiger, 2004). No mesmo sentido Vallone (2006), relata que há algumas modificações físicas entre o sistema radicular das plantas e o substrato quando se utiliza um volume reduzido para o crescimento das mudas, proporcionando uma maior concentração de raízes.

Freitas et al. (2005) ao estudarem diferentes recipientes e substratos na produção de mudas de eucalipto, afirmam que a maior quantidade de raízes finas no sistema radicular é um fator que pode ter uma interferência positiva direta no campo, pois elas terão uma maior adaptabilidade a condições de estresse ambiental, garantindo maior percentual de sobrevivência e crescimento inicial.

Na Tabela 5, nota-se o que já havia sido evidenciado em análises anteriores, onde a cultivar Acauã se manteve significativamente superior às demais, apresentando uma média de massa seca da raiz de 2,29 gramas e a Catuaí 144 a menor média com 1,99 gramas. Tais resultados permitem inferir que a cultivar Acauã, independente do substrato ou do recipiente, apresentou melhor desempenho. Silva et al. (2012) testando diferentes cultivares de café em dois sistemas de manejo com três tipos de resíduos orgânicos, observaram que a cultivar Catuaí Vernelho IAC 44 apresentou maior massa seca das raízes quando comparado, Catucaí Amarelo 2SL e Mundo Novo IAC 379-19, destacando que o manejo convencional das mudas refletiu na maior massa seca das raízes.

Ao analisar os valores de RPAR na interação cultivares x recipientes (Tabela 6), verifica-se uma melhor relação para a cultivar Topázio 1190, Arara e Catucai 2 SL, no saquinho, sendo significativamente superiores às demais cultivares, verificando que o RAD mais adequado foi para a cultivar Topázio 1190. As cultivares dentro do tubete não apresentaram diferença significativa, apresentando uma média geral de 2,61, o que foi inferior ao proposto por Marana, et al. (2008), que ao estudarem o efeito de diferentes formulações de substrato para o preenchimento do tubete, concluíram que o intervalo ideal desse parâmetro de qualidade deve ficar entre 4 a 7. Os valores encontrados para o RPAR, indicam que o recipiente influencia diretamente na qualidade das cultivares, apresentando o tubete os menores valores de RPAR (Tabela 6). 
Tabela 6. Parâmetro de crescimento: relação da massa seca da parte aérea com a massa seca de raízes (RPAR) para a interação: cultivares x recipiente e recipientes x substrato; e relação da altura parte aérea com o diâmetro do coleto (RAD) para a interação: cultivares $x$ recipiente e recipientes x substrato para de mudas de café arábica, Inconfidentes- MG.

\begin{tabular}{|c|c|c|c|c|c|c|c|c|}
\hline \multirow{3}{*}{${ }^{1}$ Rec. } & \multicolumn{5}{|c|}{ Cultivares } & \multicolumn{3}{|c|}{ Recipiente } \\
\hline & Acauã & Arara & Catuaí & Catucaí & Topázio & ${ }^{4}$ Sub. & Tub & $\mathrm{Saq}$ \\
\hline & \multicolumn{5}{|c|}{ RPAR } & \multicolumn{3}{|c|}{ RPAR } \\
\hline${ }^{2}$ Tub. & $2,30 \mathrm{Aa}$ & $2,52 \mathrm{Aa}$ & $2,88 \mathrm{Aa}$ & $2,69 \mathrm{Aa}$ & $2,68 \mathrm{Aa}$ & ${ }^{5}$ Com. & $3,07 \mathrm{Ab}$ & $6,08 \mathrm{Aa}$ \\
\hline${ }^{3} \mathrm{Saq}$. & $6,34 \mathrm{Bb}$ & $5,62 \mathrm{Ba}$ & $6,61 \mathrm{Bc}$ & $5,56 \mathrm{Ba}$ & $5,66 \mathrm{Aa}$ & ${ }^{6} \mathrm{Pad}$. & $2,16 \mathrm{Bb}$ & $5,84 \mathrm{Aa}$ \\
\hline Rec. & \multicolumn{5}{|c|}{ RAD } & \multicolumn{3}{|c|}{ RAD } \\
\hline Tub. & $3,52 \mathrm{Aa}$ & $4,11 \mathrm{Ab}$ & $4,03 \mathrm{Ab}$ & $4,32 \mathrm{Ab}$ & $4,20 \mathrm{Ab}$ & Com. & $4,70 \mathrm{Ab}$ & $5,87 \mathrm{Aa}$ \\
\hline Saq. & $5,69 \mathrm{Bb}$ & $5,69 \mathrm{Bb}$ & $6,11 \mathrm{Bc}$ & $5,99 \mathrm{Bb}$ & $5,62 \mathrm{Ba}$ & Pad. & $3,37 \mathrm{Bb}$ & $5,77 \mathrm{Aa}$ \\
\hline
\end{tabular}

${ }^{1}$ Recipiente; ${ }^{2}$ Tubete; ${ }^{3}$ Saquinho; ${ }^{4}$ Substrato; ${ }^{5}$ Comercial; ${ }^{6}$ Padrão. *Médias seguidas das mesmas letras maiúsculas na coluna e minúsculas na linha não diferem entre si pelo teste de Tukey a $5 \%$ de significância.

Fonte: Autores (2020).

Os índices de RPAR, na interação substrato x recipiente, foram diferentes de maneira significativa, a favor do uso do substrato comercial no tubete com RPAR de 3,07, apresentando também os melhores resultados para MSPA e MSSR (Tabela 4). Segundo Vallone (2003), valores mais baixos de RPAR são desejáveis, desde que o crescimento da parte aérea, quanto do sistema radicular seja equilibrado e satisfatório. Não foram verificadas diferenças significativas entre as médias quando os substratos foram submetidos ao saquinho. Verifica-se também que o uso do saquinho para os dois substratos sempre apresentou os maiores valores de RPAR, corroborando com Oliveira e Miglioranza (2015), que demonstra que os recipientes de maior volume apresentam maior relação para este parâmetro.

Já para a relação da altura de planta com o diâmetro de caule (RAD), Tabela 6, houve diferença significativa entre as cultivares para ambos os recipientes, sendo o uso do tubete com RAD mais adequado. Nos resultados obtidos dentro do tubete, nota-se que a menor relação foi obtida pela cultivar Acauã, sendo ela a única que ficou dentro do estabelecido por Marana et al. (2008), que recomendam valores entre 3,5 a 4, sendo que este resultado vai de encontro com o desempenho desta cultivar no tubete para os parâmetros de crescimento (Tabelas 2 e 3 ).

Os valores de RAD obtidos pelas demais cultivares ficaram bem próximos a 4 (Tabela 6), mostrando que para esse parâmetro de qualidade todas as cultivares mantiveram um comportamento esperado, considerado por Dardengo et al. (2013) como ideal para o seu bom pegamento no campo. O mesmo autor também verificou que as mudas produzidas em tubete apresentaram menor RAD em relação as mudas produzidas em sacolas.

Para o saquinho, na Tabela 6, observa-se que todas as cultivares apresentaram valores maiores ao estabelecido por Marana et al. (2008). Sendo que essa superioridade do RAD para recipientes de maior capacidade volumétrica já era esperado em função do maior volume e consequentemente, uma maior disponibilidade nutricional para o crescimento das mudas, provocando, por consequência um maior ganho em altura das mudas, além do menor diâmetro de caule, efeito esse parecido ao estiolamento, provocado por aumento dos teores nutricionais neste recipiente quando comparado ao tubete. Ao analisar isoladamente, nota-se que a Catuaí 144 apresentou, novamente, uma maior média, mostrando um crescimento excessivo em altura, provando o que já foi relatado anteriormente para RPAR.

Não foram verificadas diferenças significativas para ambos os substratos dentro de saquinho, indicando que as mudas produzidas neste recipiente, independente da composição dos substratos estudados, possuem relações semelhantes de RAD (Tabela 6). Nesta mesma interação o menor resultado com o uso do tubete foi para o uso do substrato padrão a qual apresentou também a menor altura (Tabela 2). Já os resultados obtidos em tubetes foram inferiores aos do saquinho, para ambos os substratos, 
nos quais os valores de RAD variaram entre 3,37 para substrato padrão a 4,70 para substrato comercial. Esse maior resultado no saquinho apresenta relação com a maior altura verificada para as mudas produzidas neste recipiente (Tabela 2).

Dessa forma, maiores valores de RPAR não são indicados, pois acabam provocando um desequilíbrio de crescimento entre a parte aérea, com o sistema radicular da planta e o diâmetro do coleto. Portanto valores de RPAR maiores do que 3 podem comprometer o crescimento das mudas no campo em função da maior taxa evapotranspirativa. Estes resultados também são validados pelo IQD (Tabela 7) no recipiente tubete apresentando os maiores valores, principalmente com o uso do substrato comercial. Esses resultados são contraditórios aos encontrados por Marana et al. (2008), a qual aponta que índices superiores a 7, o crescimento do sistema radicular aparentemente foi insuficiente e valores inferiores a 4 indicam que a muda não teve um bom crescimento da parte aérea.

Tabela 7. Parâmetro de qualidade: índice de qualidade de Diskson (IQD) para a interação: Cultivares x substrato e recipientes x substrato em mudas de café arábicas, Inconfidentes- MG.

\begin{tabular}{|c|c|c|c|c|c|c|c|c|}
\hline \multirow{2}{*}{${ }^{1}$ Sub. } & \multicolumn{5}{|c|}{ Cultivares } & \multirow{2}{*}{ Sub. } & \multicolumn{2}{|c|}{ Recipiente } \\
\hline & Acauã & Arara & Catuaí & Catucaí & Topázio & & Tubete & Saquinho \\
\hline & & & IQD & & & & IQD & \\
\hline${ }^{2} \mathrm{Com}$. & $1,42 \mathrm{Aa}$ & $1,24 \mathrm{Aa}$ & $1,14 \mathrm{Aa}$ & $1,19 \mathrm{Aa}$ & $1,16 \mathrm{Aa}$ & Com. & $1,45 \mathrm{Aa}$ & $1,00 \mathrm{Ab}$ \\
\hline${ }^{3} \mathrm{Pad}$. & $1,23 \mathrm{Ba}$ & $1,03 \mathrm{Bc}$ & $1,03 \mathrm{Ac}$ & $1,12 \mathrm{Ab}$ & $1,23 \mathrm{Aa}$ & Pad. & $1,24 \mathrm{Ba}$ & $1,01 \mathrm{Aa}$ \\
\hline
\end{tabular}

${ }^{1}$ Substrato; ${ }^{2}$ Comercial; ${ }^{3}$ Padrão. *Médias seguidas das mesmas letras maiúsculas na coluna e minúsculas na linha não diferem entre si pelo teste de Tukey a 5\% de significância.

Fonte: Autores (2020).

Observa-se que a utilização do saquinho, proporcionou um maior aumento dos valores de RAD, as quais cresceram mais em altura do que em diâmetro do coleto, fato esse que não é desejável na produção de mudas cafeeiras. Provavelmente isso está associado ao maior fornecimento de nutrientes, principalmente o nitrogênio, provocando um aumento da altura da planta em detrimento do crescimento radicular. Oliveira e Miglioranza (2015) estudando o efeito de diferentes tamanhos e cores de recipientes não verificaram o efeito da interação ou dos tratamentos isolados nos valores de RAD, com valores variando entre 6,21 a 6,46. Já Santinato et al. (2019) verificaram em sacolinhas que o uso do substrato padrão produz mudas com RAD estatisticamente iguais ao uso de diferentes concentrações de esterco suíno com os valores situados entre 5,25 a 5,95.

Segundo Dardengo et al. (2013) e Marana et al. (2008), esses índices de qualidade (RAD e RPAR), servem para avaliar a real qualidade das mudas, já que essas informações auxiliam no manejo adequado das mesmas no viveiro.

Analisando o desempenho das cultivares (Tabela 7) pelo cálculo do IQD foi possível constatar que não houve diferença significativa para as cultivares dentro do substrato comercial. As cultivares que sobressaíram em qualidade de mudas, dentro do substrato padrão, foram a Acauã e a Topázio 1190, apresentando os maiores valores de IQD. A cultivar Topázio 1190 foi a única que apresentou o menor IAF e melhor relação de RPAR e RAD com o uso do saquinho para os três parâmetros avaliados conjuntamente, refletindo nos melhores valores para o IQD indicando o seu equilíbrio de crescimento, sendo igual a cultivar Acauã a única com o uso de tubete, que apresentaram as melhores relações de RPAR e RAD e maiores crescimentos da MSPA e MSSR.

Já para a comparação entre os substratos para o IQD, três das cinco cultivares avaliadas se mantiveram iguais estatisticamente. Sendo a Acauã e a Arara as únicas que apresentaram superioridade para o substrato comercial, sendo as médias de 1,42 e 1,24 , respectivamente.

Ao se calcular o índice de qualidade de Dickson (IQD) (Tabela 7), foi possível constatar que os resultados obtidos na interação substrato recipiente variaram entre 1,00 a 1,45. Esses valores de IQD são superiores ao estabelecido por Hunt (1990), que estabeleceu o valor mínimo de 0,20 para se obter uma muda de qualidade. Com isso, pode-se afirmar que o IQD é um bom 
indicador da qualidade das mudas, por considerar em seu cálculo a robustez a massa seca total e o equilíbrio da distribuição da matéria seca (RAD e RPAR), sendo considerada como uma medida morfológica integrada (Dardengo et al., 2013).

Ao analisar o IQD, da interação recipiente x substrato nota-se que não houve diferença significativa para ambos os substratos quando as mudas foram produzidas no saquinho. Resultado que permite inferir que o viveirista ou o produtor deva fazer do uso do substrato mais acessível e de maior facilidade de aquisição para o crescimento inicial das mudas. Já para o tubete, houve uma superioridade quando as mudas foram produzidas com substrato comercial, apresentando uma média de 1,45 (Tabela 7), demonstrando mais uma vez que o uso desse conjunto (tubete: substrato comercial), foi superior em qualidade na produção de mudas de cafeeiro. Isso porque, quanto maior for o valor obtido pelo IQD melhor foi a relação de MSPA e MSSR (Dardengo et al., 2013).

A avaliação dos tratamentos pelo dendograma foi realizada com o corte formando dois grandes grupos (Figura 1). O primeiro grupo foi formado pelos tratamentos 6 a 10 que apresentam em comum a utilização de tubetes com substrato padrão. No segundo grande grupo há dois subgrupos de destaque. Sendo o primeiro subgrupo formado pelos tratamentos constituídos pelo uso do tubete com substrato comercial sendo descrito pelos tratamentos de 1 a 5 e o segundo subgrupo formado pelos tratamentos de 11 a 20 tendo como singularidade o uso do recipiente saquinho. Como foi observado na análise univariada, os melhores resultados foram obtidos com o uso de substrato comercial em tubetes, caracterizado de maneira correlata pelo primeiro subgrupo. Os piores resultados da análise univariada foram para o uso do tubete com substrato padrão representado pelo grupo 1.

Figura 1. Dendrograma resultante da análise de agrupamento dos 20 tratamentos, utilizando se a distância generalizada de mahalanobis pelo método de agrupamento de UPGMA ( $\mathrm{P}=$ Padrão; $\mathrm{C}=$ Comercial; $\mathrm{T}=$ Tubete; $\mathrm{S}=\mathrm{Saquinho}$; Ca, Catuai 144 , To= Topázio $=\mathrm{A}=$ Arara; Ac= Acauã, Cc= Catucai 2 SL Tratamentos: 1 TCCa; 2 TCA; 3 TCTo; 4 TCCc; 5 TCAc; 6 TPCa; 7 TPA; 8 TPTo; TPCc; 10 TPAc; 11 SCCa, 12 SCA; 13 SCTo; 14 SCCc; 15 SCAc; 16 SPCa, 17 SPA; 18 SPTo; 19 SPCc; 20 SPAc.

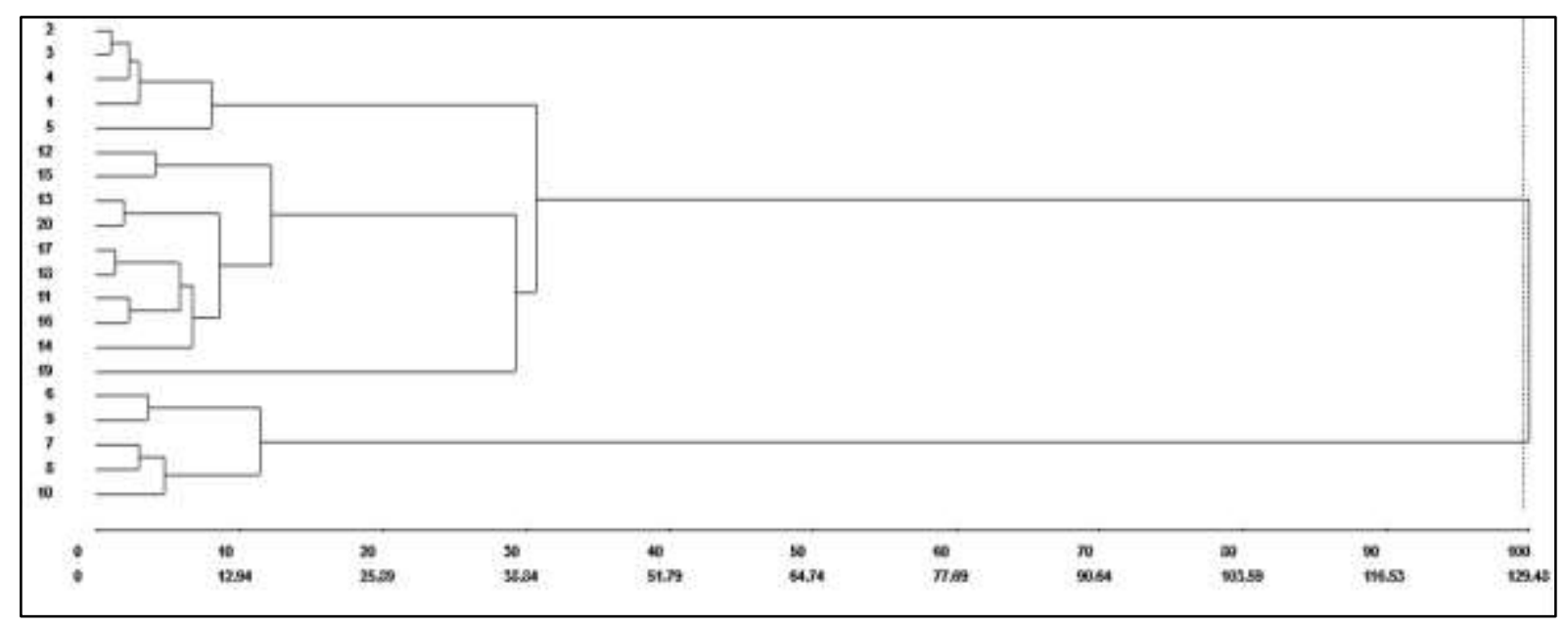

Fonte: Autores (2020).

Pela análise da estimação da contribuição relativa de cada variável para a expressão da diversidade dos tratamentos (Tabela 8), verificou-se que a altura de planta e o RAD contribui com 99,37\% para a divergência entre os tratamentos. Apresentam estas variáveis em comum a altura de plantas pois, se a altura for demasiada reduz a qualidade das mudas, contudo se for de pequena magnitude, a planta ainda não apresenta a qualidade satisfatória para ser levada a campo, sendo que a análise conjunta destas variáveis indicam que quanto maior a altura e o RAD pior a qualidade das mudas, inferindo que as mesmas 
podem estar estioladas em função de excesso de nitrogênio ou sombra, servindo como parâmetro para discriminar as melhores e piores mudas.

Tabela 8. Contribuição relativa dos 8 caracteres agronômicos avaliados para o estudo de diversidade dos tratamentos, segundo o critério de Singh (1981).

\begin{tabular}{cccccc}
\hline Variável & S.j & Valor em $\%$ & Variável & S.j & Valor em \% \\
\hline Altura planta & 2573734.24 & 49.63 & RPAR & 7585.61 & 0.15 \\
RAD & 2579524.91 & 49.74 & MSPA & 5068.52 & 0.09 \\
MST & 9622.891 & 0.19 & IQD & 2265.37 & 0.04 \\
IAF & 6002.22 & 0.12 & MSSR & 2002.44 & 0.04 \\
\hline
\end{tabular}

Fonte: Autores (2020).

Os tratamentos que tiveram o melhor IQD e MSSR foram os de número 1, 2, 3, 4 e 5; apresentando como mesma particularidade o uso de tubete e substrato comercial (Figura 2). O substrato que menos contribui para o IQD e MSSR foi o substrato padrão independentemente do recipiente utilizado (tratamentos de 6 a 10 e 16 a 20). Com o uso do substrato comercial na sacolinha, os tratamentos 11 e 14 tiveram piores resultados para a qualidade das mudas. Jaeggi et al. (2020) afirma que a análise de componentes principais é uma ferramenta exploratória importante que permite identificar as variáveis mais importantes na identificação dos tratamentos na formação de mudas de café.

Pelos resultados obtidos, verifica-se superioridade das mudas produzidas em tubetes, contudo há uma discussão quanto ao pegamento das mudas de café produzidas em sacolas de polietileno e tubete. Dessa forma, Marchi et al. (2002) afirmam em sua pesquisa, que em um solo Argissolo Vermelho Amarelo distrófico, em sistema convencional de plantio, o pegamento das mudas é igual em ambos recipientes quando as condições climáticas são favoráveis. Dardengo et al. (2018) em pesquisa mais recente com mudas de café conilon, produzidas em tubetes e sacolas de polietileno também não verificou que o tipo de recipiente interferiu no crescimento das mudas no campo. 
Figura 2. Dendrograma resultante da análise de agrupamento dos 20 tratamentos, utilizando-se a distância generalizada de mahalanobis pelo método de agrupamento de UPGMA ( $\mathrm{P}=$ Padrão; $\mathrm{C}=$ Comercial; $\mathrm{T}=$ Tubete; $\mathrm{S}=\mathrm{Saquinho}$; Ca, Catuai 144 , To= Topázio $=\mathrm{A}=$ Arara; Ac= Acauã, $\mathrm{Cc}=$ Catucai 2 SL Tratamentos: 1 TCCa; 2 TCA; 3 TCTo; 4 TCCc; 5 TCAc; 6 TPCa; 7 TPA; 8 TPTo; TPCc; 10 TPAc; 11 SCCa, 12 SCA; 13 SCTo; 14 SCCc; 15 SCAc; 16 SPCa, 17 SPA; 18 SPTo; 19 SPCc; 20 SPAc.

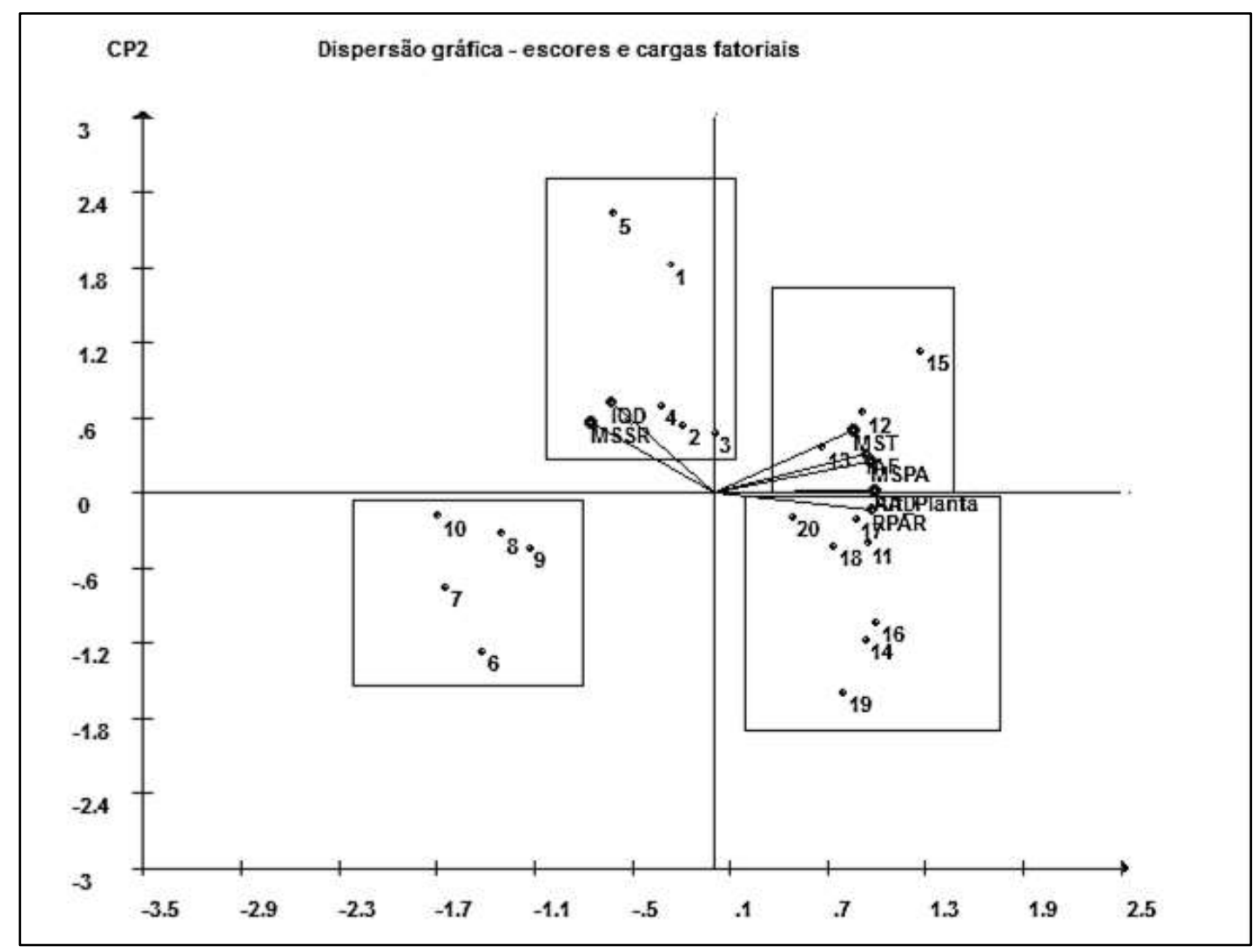

Fonte: Autores (2020).

\section{Considerações Finais}

Os diferentes recipientes e substratos utilizados influenciam significativamente o crescimento das mudas de cafeeiro. $\mathrm{O}$ saquinho, preenchidos com substrato comercial, proporcionou mudas com maior crescimento. O tubete, preenchido com substrato comercial, proporcionou mudas de melhor qualidade. A cultivar que apresentou um maior desequilíbrio foi a Catuaí 144, no saquinho.

As cultivares que apresentam melhores IQD são a Acauã com uso de tubete em substrato comercial e a Topázio 1190 na sacolinha. A variável que mais contribui para o IQD foi a MSSR. O substrato padrão limitou o crescimento das raízes.

A escolha do recipiente e substrato para a produção de mudas de café é uma etapa muito importante para se proporcionar uma melhor qualidade nas lavouras.

\section{Agradecimentos}

Os autores expressam seus agradecimentos ao IFSULDEMINAS (Instituto Federal Educação, Ciência e Tecnologia do Sul de Minas), pelo apoio concedido durante a condução do trabalho, à FAPEMIG (Fundação de Amparo à Pesquisa do estado de Minas Gerais), ao CNPq (Conselho Nacional de Desenvolvimento Científico e Tecnológico), à CAPES (Coordenação de Aperfeiçoamento de Pessoal de Nível Superior), pela concessão de bolsas de iniciação científica, mestrado e doutorado. 


\section{Referências}

Andrade Neto, A., Mendes, A. N. G., \& Guimarães, P. T. G. (1999). Avaliação de substratos alternativos e tipos de adubação para a produção de mudas de cafeeiro (Coffea arabica. L.) em tubetes. Ciência e Agrotecnologia, Lavras, 23(2), 270-280.

Bachião, P. O. B., Maciel, A. L. R., Avila, R. G., \& Campos, C. N. (2018). Crescimento de mudas de cafeeiro em tubetes com fertilizante de liberação lenta. Revista Agrogeoambiental, 10, 105-115.

Campos, K. P. de. Produção de mudas de cafeeiro (Coffea arabica L.) em diferentes espaçamentos, subtratos, adubações e tamanhos de tubetes. 2002. 90f. Dissertação (Mestrado em Fitotecnia) - Universidade Federal de Lavras, 2002.

Conab, Companhia Nacional de Abastecimento, 2018. Levantamento de Safra Brasileira Café, Safra 2018, quarto Levantamento, Brasília. https://www.conab.gov.br/info-agro/safras/cafe

Cunha, R. L., Souza, C. A. S., Neto, A. A., Melo, B., \& Correia, J. F. (2002). Avaliação de substratos e tamanho de recipientes na formação de mudas de cafeeiro (Coffea arabica L.) em tubetes. Ciência e Agrotecnologia, Lavras, 26 (1), 7-12.

Cruz, C. D. (2013). Genes - a software package for analysis in experimental statistics and quantitative genetics. Acta Scientiarum, 35(3), 271-276

Dardengo, J. D., Soua, E. F., Reis, E. F., \& Gravina, G. A. (2013). Crescimento e qualidade de mudas de café conilon produzidas diferentes recipientes e níveis de sombreamento. Coffee Science, Lavras, 8 (4), 500-509.

Dardengo, M. C. J. D., Pereira, L. R., Sousa, E. F. De., \& Reis, E. F. (2018). Repercussions of the Level of Shading and the Type of Container in the Seedling Stage on the Growth of Irrigated and Non-irrigated Coffee Plants in the Field. Journal of Experimental Agriculture International, $27,1-13$.

Dias, F. P., Souza, C. A. S., Mendes, A. N. G., Carvalho, S. P. De., Raso, B. S. M., \& Botelho, C. E. (2005). Caracterização de progências do cafeeiro (Coffea arabica L.) selecionadas em Minas Gerais: II- Carateres relacionados à produção. Revista Ceres, Viçosa, 52, 85-100.

Dickson, A., Leaf, A. L., \& Hosner, J. F. (1960). Quality appraisal of white spruce and white pine seedling stock in nurseries. Forest Chronicle, 36, 10-13.

Ferreira, D. F. (2014). SISVAR: sistema de análise de variância, Versão 5.3, Lavras/ DEX.

Freitas, A. S., De., Barroso, D. G., Carneiro, J. G. A., Penchel, R. M., Lamônica, K. R., \& Ferreira, D. A. (2005). Desempenho radicular de mudas de eucalipto produzidas em diferentes recipientes e substratos. Revista Árvore, Viçosa, 29 (6), 853-861.

Gomes, J. M., \& Silva, A. R. Da. (2004). Os substratos e sua influência na qualidade de mudas. In: Barbosa, J. G., Prietro, M. H. E., Pedrosa, M. W., \& Sediyama, M. A. N. Nutrição e adubação de plantas cultivadas em substrato. Viçosa: UFV, 190-225.

Hunt, G. A. (1990). Effect of styroblock design and cooper treatment on morphology of conifer seedlings. In: Rose, R., Campbell, S. J., \& Landis, T. D. Target seedling symposium: Proceedings, combined meeting of the Western Forest Nursery Associations. Fort Collins-CO: Department of Agriculture, Forest Service, Rocky Mountain Forest and Range Experiment Station, 286 p

Jaeggi, M. E. P. C., Rocha, R. S., Pereira, I. M., Da Cruz, D. P., Batista, J. N., De Ká, R., Parajara, M. Do C., Da Silva, S. F., Rogé, A., Oliveira, W. B. Dos S., Da Fonseca, A. S., Gravina, G. De A., \& Luí, W. (2020). Multivariate analysis in the evaluation of sustrate quality and containers in the production of Arabica coffee seedlings. African Journal of Agricultural Research, 15, 457-463.

Kämpf, A. N. (2002). O uso de substrato em cultivo protegido no agronegócio brasileiro. In: Furlani, A. M. C. et al. Caracterização, manejo e qualidade de substratos para produção de plantas.: Instituto Agronômico, 1-6.

Marana, J. P., Miglioranza, E., Fonseca, E. P., \& Kainuma, R. H. (2008). Índices de qualidade e crescimento de mudas de café produzidas em tubetes. Ciência Rural, Santa Maria, 38 (1), 39-45.

Marchi, E. C. S., Campos, K. P. De., Correa, J. B. D., Guimaraes, R. J., \& Souza, C. A. S. (2003). Sobrevivência. de mudas de cafeeiro produzidas em sacos plásticos tubetes no sistema convencional e plantio direto, em duas classes de solo. Revista Ceres, Vicosa, 50 (290), 407-416.

Matiello, J. B. (2005). Cultura de café no Brasil: novo manual de recomendações: Mapa/Procafé.

Ministério da Agricultura, Pecuária e Abastecimento. (2020). Cultivares registradas de café arábica. http://sistemas.agricultura.gov.br/snpc//cultivarweb/.

Ministério da Agricultura, Pecuária e Abastecimento - MAPA. (2017). Café no Brasil. www.agricultura.gov.br/assuntos/politica-agricola/cafe/cafeiculturabrasileira\#section-1.

Oliveira, C. L. G., \& Miglioranza, E. (2015). Quality levels of organic coffee seedlings in black and whitenonwoven fabric (NWF) containers of various sizes.. African Journal of Agricultural Research, 10, 886-894.

Pereira, T. B., Carvalho, J. P. F., Botelho, C. E., Resende, M. D. V. De., Rezende, J. C. De., \& Mendes, A. N. G. (2013). Eficiência de seleção de progênies de café $\mathrm{F}_{4}$ pela metodologia de modelos mistos (REM/BLUP). Bragantia, Campinas, 72(3), 230-236.

Samôr, O. J. M., Carneiro, J. G. A., Barroso, D. G., \& Leles, P. S. S. (2002). Qualidade de mudas de angico e sesbânia, produzidas em diferentes recipientes e substratos. Revista Árvore, Viçosa, 26 (2), 209-215.

Santana, S. L. De A., Cogo, F. D., Ribeiro, B. T., Campos, K. A., \& Morais, A. R. (2011). Adição Resíduos orgânicos ao substrato para produção de mudas de café em tubetes. Revista Agrogeoambiental, 3, 9-13.

Silva, E. A., Cogo, F. D., Almeida, S. L. S., Campos, K. A., \& Morais, A. R. (2012). Desenvolvimento de mudas de cafeeiro Coffea arabica L sob diferentes composições de substratos. Enciclopédia Biosfera, 8, 337-346. 
Research, Society and Development, v. 10, n. 2, e2810212073, 2021

(CC BY 4.0) | ISSN 2525-3409 | DOI: http://dx.doi.org/10.33448/rsd-v10i2.12073

Singh, D. The relative importance of characters affecting genetic divergence. The Indian Journal of Genetic and Plant Breeding, 41 (2), 237-245, 1981.

Taiz, L., \& Zeiger, F. (2004). Fisiologia Vegetal. (3a. ed.): Artmed, 719 p.

Vallone, H. S. (2003). Produção de mudas de cafeeiro (Coffea arabica L.) em tubetes com polímero hidroretentor, diferentes substratos e adubações. 75 p. Dissertação (Mestrado) - Universidade Federal de Lavras, Lavras, MG.

Vallone, H. S. (2006). Recipientes e substratos na produção de mudas e no desenvolvimento inicial de cafeeiros (Coffea arabica L.). Lavras, 89p. 